\title{
Recent Educational Experiences in Electric Machine Maintenance Teaching
}

\author{
http://dx.doi.org/10.3991/ijep.v3iS3.2742 \\ J. Antonino-Daviu, J. Pons-Llinares, V. Climente-Alarcón \\ Universitat Politècnica de València, Valencia, SPAIN
}

\begin{abstract}
Maintenance of electric machines and installations is a particularly important area; eventual faults in these devices may lead to significant losses in terms of time and money. The investment and concern in developing proper maintenance protocols have been gradually increasing over recent decades. As a consequence, there is a need to instruct future engineers in the electric machines and installations maintenance area. The subject 'Maintenance of Electric Machines and Installations' has been designed under this idea. It is taught within an official master degree in Maintenance Engineering. This work describes the educational experiences reached during the initial years of the teaching of the subject. Aspects such as student profiles, subject approaches, design of the syllabus, methodology and structure of the laboratory sessions are remarked in the work. In addition, the paper discusses other educational strategies which are being introduced to increase the interest in the subject, such as integration of Information and Communication Technologies (ICT), promotion of the collaborative work, inclusion of the possibility of remote learning or development of new assessment systems.
\end{abstract}

Index Terms-industrial maintenance; electric machines; collaborative work; e-learning; teaching platforms.

\section{INTRODUCTION}

The evolution of industrial maintenance over the last century clearly reflects the increasing importance and attention that this area has been progressively attracting. Synthesizing, the history of industrial maintenance until the early 2000's can be divided into three main stages or generations [1]: The first generation systems (1930's50 's) were characterized by the absence of a proper systematic maintenance. They relied on a very simple idea: "repair after the fault occurs". These rudimentary types of maintenance had very important drawbacks, such as unexpected downtimes with consequent time and money losses as well as other significant collateral damages. As a consequence, a second generation group of maintenance systems raised [1950's-70's]. This group incorporated aspects such as equipment inspections done at fixed intervals as well as component substitutions before reaching the end of their estimated life. Work planning and control systems as well as computerization of some maintenance tasks were also introduced. Despite the indubitable advances of these systems, some important constraints still remained. Among them, the lack of reliability of the life estimation statistical techniques, which may lead to waste a significant portion of the potential remaining life of replaced components or, on the contrary, the possibility of coming across a failure before the end of the predicted component life. The search for ways able to maximize the life of the assets led to the development of a third generation of maintenance systems since the mid 70's. This group includes more advanced maintenance modalities, emphasizing aspects such as: condition monitoring, design for reliability and maintainability, hazard studies, small and fast computers, failure modes and effects analyses, experts systems and multiskilling and teamwork [2].

Electric machines and installations are particularly relevant in the industrial context; while static and rotating electric machines are widely spread in the industry, electrical installations are crucial parts of the industrial facilities and premises. Therefore, proper maintenance of all these electric elements has become particularly important in the today societies. In particular, with regards to the electric machines, induction (or asynchronous) motors are of special interest; they are the most used rotating electric machines in industry, being considered as the "industry workhorses" by some authors [3]. These machines intervene in a countless number of applications, some of them critical. Hence, their sudden failure may lead to severe consequences. Despite they are quite robust machines (especially, the squirrel cage motors), they may undergo several types of failures: broken rotor bars, eccentricities, bearing faults, stator turn faults, etc... [3], that can even put the machine out of service.

It can be said that electric machines maintenance has run in parallel with industrial maintenance. While rudimentary types of electric machine maintenance were based on simple repair after the machine had failed (corrective maintenance), the most modern maintenance modalities rely on monitoring certain quantities of the machine (currents, voltages, vibrations, temperatures, etc...) and analyzing them properly, in order to detect possible indicators informing that an eventual fault is stating (predictive maintenance). For the analysis of the aforementioned quantities, suitable signal processing tools must be used. The most common technique is based on analyzing the stator current demanded by the machine during its steady-state operation via the Fast Fourier Transform (FFT). This tool allows extracting the frequency content of the analyzed signal. The underlying idea of this approach consists of studying the amplitudes of characteristic frequency components in the spectrum, each associated with a certain failure. Thus, a high amplitude of the fault-related frequency (or 'frequency peak') in the FFT spectrum will indicate the presence of the fault in the machine. As an example, Fig.1 (a) shows the FFT spectrum of the steady-state current for a healthy motor; a single 'frequency peak' appears at the supply frequency $(50 \mathrm{~Hz})$ (always present). Fig 1(b) shows the same spectrum but for a faulty motor (motor with two broken rotor 


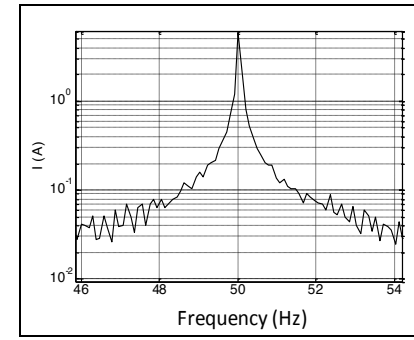

(a)

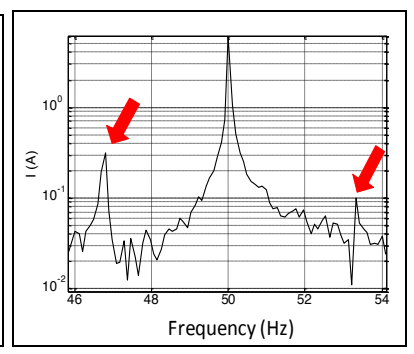

(b)
Figure 1. FFT of the steady-state current for: (a) healthy induction motor; (b) Loaded motor with 2 broken bars

bars); two frequency peaks can be observed around the supply frequency peak. These components, known as sideband harmonics, are caused by the failure. Hence, their detection constitutes a reliable indicator informing on the presence of the fault.

This classical fault diagnosis method, though widely spread in the industry, has some important drawbacks which have been studied in detail in the literature [4-6]. These disadvantages can be summarized in the fact that the approach is only strictly valid when the machine operates under a pure stationary condition; this situation is uncommon in many industrial applications, in which the presence of transients is rather usual (machines driving mills, pumps, compressors, gear reducers...). As a consequence, the reliability and generality of the approach is uncertain, under an industrial perspective.

Due to the problems of the classical steady-state-based diagnosis method, since the early 2000's, a novel approach was proposed. This new methodology is based on the analysis of the current demanded by the machine, not during steady-state but during its transient operation (most of the works are focused on a particular transient: the startup of the machine). The underlying idea is to identify characteristic patterns caused by the time-frequency (t-f) transient evolution of particular fault-related components which are present in the current signal [5-6]. The process relies on analyzing the transient current signal by using suitable tools, obtaining a time-frequency representation of that signal. Once the t-f representation is obtained, fault-related patterns are identified (if present) in the resulting t-f map. In order to apply this approach, the FFT is no longer valid (since it implies a loss of the time information); suitable time-frequency decomposition (TFD) tools, enabling the analysis of non-stationary signals and providing their $t-f$ representation, must be used. Among the wide range of available TFD tools (Short Time Fourier Transform, Wigner-Ville Distributions, Hilbert-Huang Transforms, Wavelet transforms...), the Discrete Wavelet Transform (DWT) is the one used in the laboratory sessions due to its simplicity, reduced computational burden and general availability in many commercial software packages (such as Matlab) [6].

An example of the application of the novel transient based approach is shown in Fig. 2. Fig. 2(a) shows the DWT of the startup current for a healthy machine and Fig. 2(b) shows the same analysis but for a machine with 2 broken bars [5-7]. A clear $\Lambda$-shaped pattern appears in the second case; it is caused by the time-frequency evolution of a broken bar-related component during the startup [57]. This pattern constitutes a reliable indicator of the presence of the failure.

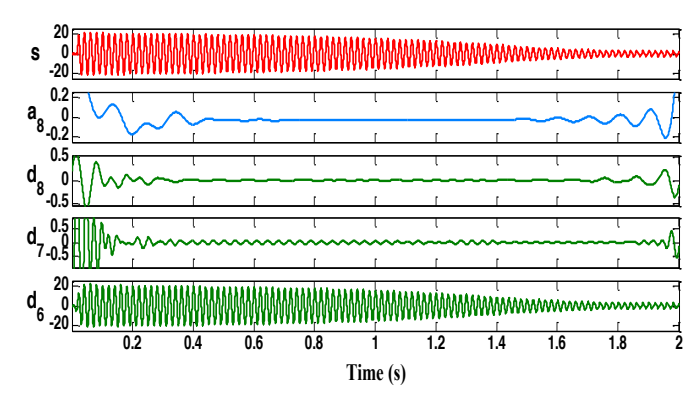

(a)

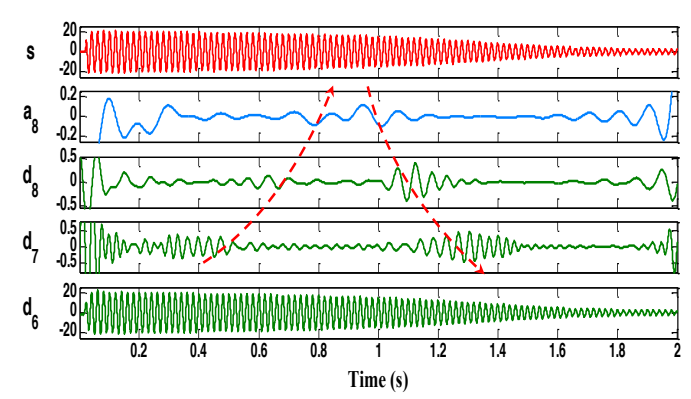

(b)

Figure 2. DWT of the steady-state current for: (a) healthy induction motor; (b) Motor with 2 broken bars

Unlike the classical method, the transient-based approach is valid regardless of the loading condition of the machine [5-7]. Moreover, it is much more reliable to detect a t-f pattern than a single frequency peak in the FFT spectrum that may be easily produced by another phenomenon [5-6]. All this leaving aside the fact that the new approach enables the diagnosis of some faults that the classical one does not [8].

The utilization of the classical FFT-based diagnosis approach in many industrial applications together with the incipient introduction of the novel transient-based diagnosis methodologies (as well as their increasing importance within the research strategies of many electric machine manufacturers) make the instruction of the students on the foundations and operation of both approaches very desirable in a subject focused on electric machines maintenance.

The aim of this paper is to discuss the most relevant educational aspects related to fault diagnosis teaching in a subject dealing with the maintenance of electric machines and installations, emphasizing potential strategies which may serve to improve the quality of the learning process. The paper is structured as follows: Section II briefly explains the educational context in which the teaching is carried out, Section III described the educational methodology with regards to theoretical and laboratory sessions, Section IV describes eventual educational enhancement strategies and, finally, in Section $\mathrm{V}$ the conclusions are explained.

\section{MaintenANCE of Electric MACHINES AND INSTALLATIONS}

The main objective of the 'Official Master Degree in Maintenance Engineering', taught in Universitat Politècnica de València is to qualify future professionals who will be in charge of the maintenance area in the corresponding company. Given the multidisciplinary nature of the maintenance, this Master degree offers a broad vision of the field, with a variety of subjects aimed to provide the 
graduates with the skill to reach a fast adaptation in every professional area. The Master includes and combines technical, economic, computer, logistic, management, etc...contents related to the maintenance area. The Master Degree is structured into 5 blocks: 'Multidisciplinary Education', 'Basic Education', 'Applied Education', 'Maintenance Engineering Practices' and 'Master Thesis'.

"Maintenance of Electric Machines and Installations" is a compulsory subject included within the aforementioned Master. It is taught during the second year of the Master and it is included within the block 'Applied Education' which groups a set of subjects which deal with practical and applied aspects related to industrial maintenance. The total number of hours assigned to face-to-face tuition is 45 ( 25 hours for theoretical lectures and 20 hours for laboratory sessions). 5 laboratory sessions have been designed; each session lasts 4 hours. Table I synthesizes the learning units of the subject as well as the number of assigned teaching hours. As it is observed, they are grouped into two main blocks: 1) Electric Machines Maintenance and 2) Electrical Installations Maintenance.

In the electric machines block, a significant effort is devoted to the part corresponding to predictive maintenance. Though corrective and preventive maintenance are also studied in detail, more attention is paid to the most modern maintenance modality, due to the greater scientific interest and complexity of this later approach. The different fault diagnosis techniques are studied, making special emphasis in those relying on current analysis. Both the conventional fault diagnosis FFT-based approach and the recent transient-based methodologies are explained. To complement the theoretical explanations, two specially designed laboratory sessions are devoted to apply the different fault diagnosis techniques (laboratory sessions 3 and 4).

One of the characteristics of the Master Degree in Maintenance Engineering is the diverse background and professional profiles of the registered students. In this regard, some of the students have just concluded their Bachelor studies and have joined the Master, as an option to increase their future career opportunities. On the other hand, there are students who have a significant professional experience, most of them in the industry. Indeed, some of these students are involved in the maintenance area and have joined the Master due to their interest in increasing their knowledge in particular areas, or as a way to get a better professional standing in their respective companies. Finally, there is a minority of students with other profiles (professionals of other sectors, retired people...). This diversity of profiles and backgrounds requires an additional effort when teaching the subject. In this sense, it becomes necessary to review some basic concepts which are needed to follow the subject and that some students lack. On the other hand, it is also important to combine a practical approach (remarking aspects that students can directly apply in their everyday life, for those students with professional experience) with a didactic vision (simplifying or clarifying practical aspects for students lacking experience).

Finally, it is interesting to note that the subject includes, in addition to its inherent professionally-oriented vision, a research-oriented perspective, instructing the students on novel techniques and methods, some in them under development, but that could have applicability in industry in a short/medium term. The main reason for this vision is
TABLE I.

STRUCTURE OF THE SUBJECT: LEARNING UNITS AND BLOCKS

\begin{tabular}{|l|c|}
\hline \multicolumn{2}{|c|}{ BLOCK 1: ELECTRIC MACHINES MAINTENANCE } \\
\hline Introduction to electrical machines & $10 \mathrm{~h}$ \\
\hline Motor, generator and transformers protection & $3 \mathrm{~h}$ \\
\hline $\begin{array}{l}\text { Corrective and preventive maintenance. Basic } \\
\text { concepts. }\end{array}$ & $2 \mathrm{~h}$ \\
\hline $\begin{array}{l}\text { Predictive maintenance: foundations and diagno- } \\
\text { sis methods }\end{array}$ & $6 \mathrm{~h}$ \\
\hline $\begin{array}{l}\text { Fault diagnosis in electrical machines: new trends } \\
\text { and techniques }\end{array}$ & $4 \mathrm{~h}$ \\
\hline BLOCK 2: ELECTRICAL INSTALLATIONS MAINTENANCE \\
\hline Bases of the installations maintenance & $2 \mathrm{~h}$ \\
\hline $\begin{array}{l}\text { Types of electrical installations. Electric Panel- } \\
\text { boards. }\end{array}$ & $4 \mathrm{~h}$ \\
\hline Maintenance of electrical industrial installations. & $5 \mathrm{~h}$ \\
\hline Maintenance of especial premises. & $3 \mathrm{~h}$ \\
\hline Practical cases & $6 \mathrm{~h}$ \\
\hline
\end{tabular}

the fact that the students can continue their studies in Doctorate programs in which it is necessary to be aware of the state of the art in maintenance field.

\section{EDUCATIONAL FACTS}

As commented above, the subject is structured in theoretical lectures (25 hours) and laboratory sessions (20 hours). Approximately, half of the total teaching hours (theory + laboratory) are devoted to electric machines maintenance and the other half is focused on electrical installations. In the electric machine maintenance part, a significant time is devoted to predictive maintenance and, more specifically, to teach the different electric machinery fault diagnosis techniques (both the classical FFT-based method and the novel transient-based approaches).

The foundations of the fault diagnosis techniques are explained during the theoretical lectures so that, during the laboratory sessions, the students can directly apply the concepts studied during the lectures. Fig. 3 shows a simplified scheme synthesizing the steps followed for the explanation of the fault diagnosis part during the lectures. As it is seen there, the process starts describing the typical failures taking place in induction motors (which is the electric machine mainly considered in the subject, due to its spread use in the industry), as well as the approximate failure rates. Afterwards, the quantities (vibrations, currents, temperatures ...) employed to diagnose each type of failure are commented and studied, analyzing their corresponding advantages and drawbacks and remarking the special virtues of current analysis.

Then, the classical method based on the FFT is explained: to this end, foundations of the signal processing tool (FFT), applicability of the approach and results interpretation, and advantages/drawbacks are successively explained and discussed. Every step illustrated by real examples, so that the students can visualize how the approach is applied to real cases. Finally, some exercises are proposed; the instructor shows several FFT spectra to the students, who must interpret them and reach a diagnosis conclusion. 


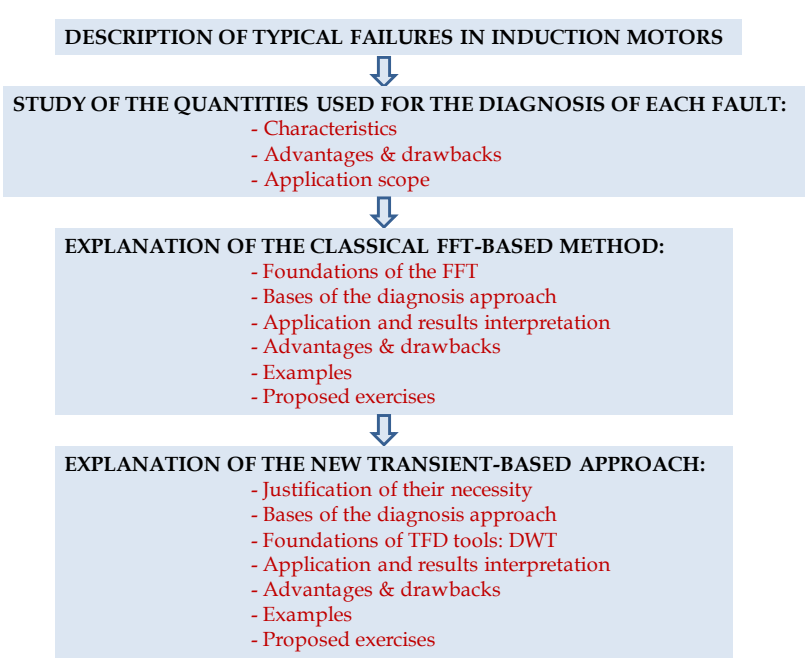

Figure 3. Simplified scheme for the explanation of the fault diagnosis part during the theoretical lectures

Afterwards, the attention is focused on the explanation of the novel transient based techniques. To this end, taking as starting point the drawbacks of the classical approach, the necessity of additional diagnosis techniques is justified. Foundations of the transient-based methodology are explained in detail, taking as a basis an illustrative type of failure (broken rotor bars). Justification of the necessity of proper signal processing tools suited for the analysis of non-stationary quantities (Time-Frequency Decomposition (TFD) tools) is given. Afterwards, foundations of some TFD tools are explained; since there is a wide variety of these tools and the available time is limited, attention is focused on a particular and simple TFD tool: Discrete Wavelet Transform (DWT) [5-6], which is taken as a basis for the explanations. The diagnosis transient-based methodology is accurately explained. Then, examples corresponding to the application of the methodology to different machines and operating conditions are shown, firstly, for the case of broken rotor bars fault and, later, for other failures, such as eccentricities. Afterwards, other examples illustrating the applicability of transient techniques relying on other tools (Hilbert-Huang Transform, Wigner-Ville Distributions, Continuous Wavelet Transform...) are shown. Finally, several practical exercises are proposed consisting of the interpretation of different timefrequency maps resulting from the application of the aforementioned TFD tools.

After the initial teaching years of the subject, an increasing interest of the students toward the fault diagnosis methodologies (both the one used in the industry and those under development) has been detected. This was reflected in the periodic questionnaires answered by the students where they reflect their opinion, as well as by informal conversations with the instructor. Moreover, the progressive improvement of the results obtained in the fault diagnosis part, both in the periodic assessment tests and in the final exam, reflects the better comprehension and assimilation of the explained concepts.

Nonetheless, there are still some issues related to the subject, in general, and to the fault diagnosis techniques teaching, in particular, that may be improved:

1. The impossibility of some students to attend some of the theoretical lectures, due to their professional duties or other special reasons, a fact that complicates them the assimilation of some concepts explained during the lectures.

2. The students' undervaluation of the importance of fault diagnosis techniques in the industrial context and the skepticism of some students toward the potential of the new transient-based methodologies.

3. The lack of an open framework in which the students can share their opinions and hold discussions about the topics studied in the subject.

4. The necessity of a proper information interchange workspace in which the students can share information and access to documents and data provided by the professor and other students.

5. The lack of an interactive assessment system to selfevaluate the studied concepts that enables the on-line evaluation of the students.

\section{ENHANCEMENT STRATEGIES}

Several educational enhancement strategies focused on the part of the subject dealing with fault diagnosis techniques are proposed in this section. These strategies have been recently designed in order to overcome the drawbacks exposed in the previous section; they are being gradually introduced. Preliminary results have shown their success with regards to the motivation and interest of the students:

\section{A. Integration of ICTs in the teaching process.}

Integration of Information and Communication Technologies (ICTs) in the teaching process is a goal that has been pursued since years ago. Significant advances have been obtained in this regard, such as the current generalized use of PoliformaT [9], the teaching multimedia platform developed by the University. The platform constitutes an excellent tool for the information interchange and communication, both between professor and students and between students. Its features allow sharing information in a very simple way. It also offers advanced features related to debate forums, assessment tools, sophisticate didactic aspects and work organization.

Moreover, data recorders with very advanced communicational features are being used during the laboratory sessions of the subject: among many other functions, they enable the remote access to the captured signals, via computers or even other devices (tablets, mobile phones...). This provides a high flexibility for the subsequent transfer and analysis of the data. On the other hand, the data can be accessed on-line so that a user working in an office can retrieve the data being captured and perform their analysis in seconds.

\section{B. Option of remote attendance}

The option following the development of the lectures in a remote way was certainly interesting for those students who were not able to attend the sessions due to their professional duties or other special reasons. In this sense, the use of the Polimedia platform, designed by the Universitat Politècnica de València, allows creating multimedia content for e-learning: preparation of teaching materials, distribution to the final user thorough different means (broadcast online, e-learning platforms, broadcast in local media such as CD, DVD, etc...)... Recording the lectures and laboratory sessions with a video camera and online transmission is one of the possibilities of the platform. 
Moreover, didactic videos on particular aspects of the sessions (assembly process, results discussions...) can be elaborated and uploaded in an open framework for further access of interested users.

\section{Providing real cases reports and organizing industrial visits}

To demonstrate the increasing importance of the fault diagnosis topic and of the condition monitoring techniques, fault cases corresponding to real machines are planned to be compiled and shown to students. The amount of available contacts of the authors both in industry and in maintenance companies has allowed obtaining a significant amount of data corresponding to real machines with rather different sizes and conditions. These real fault cases, documented both with signals and pictures, prove the importance of developing reliable techniques making possible the early diagnostic of the faults in order to avoid significant losses.

Moreover, professional visits to industrial factories and work shops are planned to be organized. During the visits, discussions with professionals working in the predictive maintenance area will be held, who will expose the importance of the research in fault diagnosic.

\section{Online framework for discussion}

An additional proposed educational enhancement for the subject relies on the creation of a novel open framework for discussion and debate on the topics taught in the sessions. In this regard, the role of the interaction tools 'Chat' and 'Forum', provided by the multimedia platform PoliformaT, is especially relevant [9]. The first enables the on-line discussion and communication between students or between students and professor while the second enables the off-line interaction. In both cases, the professor acts as a moderator, proposing discussion topics, guiding the debates or removing inappropriate comments.

\section{E. Development of a new assessment system}

The subject design includes a proper system to evaluate the correct assimilation of the threaten concepts and ideas. The proposed assessment system for the laboratory sessions is sustained on three dimensions (Fig.4):

- Assessment of the intra-group work; this evaluates the coordination and collaboration within the own group to achieve the pursued results both during the lectures and the lab sessions. It mainly considers the ability of the student to work in group. It amounts for the $40 \%$ of the laboratory sessions mark.

- Assessment of the inter-group debate; suggestions to other groups as well as collective discussions on the results are considered to evaluate this dimension. It takes into consideration the ability of the student to expose his perspective, his group interaction skills as well as his critical awareness ( $20 \%$ of the mark).

- Individual assessment; this is carried out by means of an individual test. It evaluates the assimilation and comprehension of the most important concepts $(40 \%$ of the mark).

These dimensions are accompanied by periodic autoevaluation tests that the students can answer on their own by using the PoliformaT multimedia teaching platform

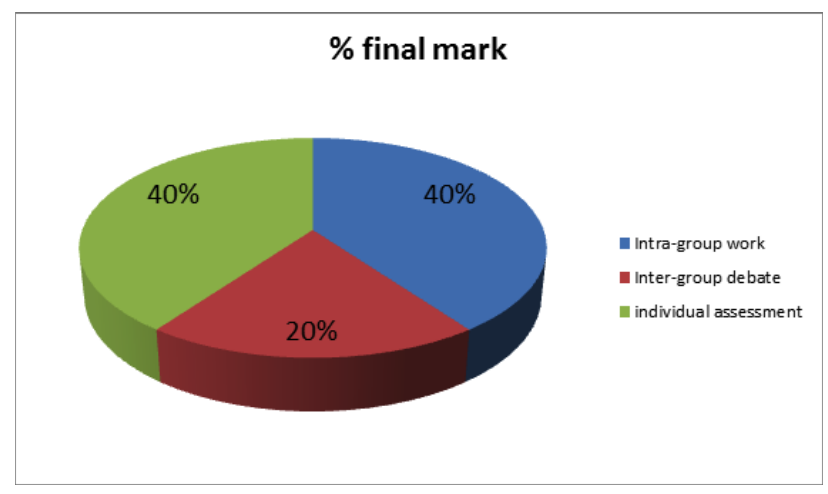

Figure 4. Proposed percentages of each assessment dimension over the final mark

\section{CONCLUSIONS}

In this paper, several educational experiences related to the teaching of fault diagnosis techniques are exposed and described. These experiences have been lived within the context of a subject dealing with the maintenance of electric machines and installations. In the subject, two fault diagnosis approaches are explained and analysed; the conventional one (widely used in the industry), based on the FFT analysis of the steady-state current and the new one, relying on the analysis of transient currents (e.g., the startup current).

In the paper, the underlying problematic of the subject, where students with rather different profiles and educational backgrounds coexist, is discussed. Also, the different approaches (professionally-oriented vs. researchfocused) employed during the teaching process are also commented.

Exposition of the proposed educational methodology is carried out, revealing the existence of some issues still pending to be solved. In this regard, several educational strategies for the enhancement of the subject (both theoretical lectures and laboratory sessions) are discussed.

Preliminary results obtained up to date reveal the success of the educational methodology, proven by the improvement of the results obtained by the students and by the evaluation obtained in the periodic questionnaires in which they express their opinion on the subject.

\section{ACKNOWLEDGMENT}

This work was supported by the Conselleria d'Educació, Formació i Ocupació of the Generalitat Valenciana, in the framework of the "Ayudas para la Realización de Proyectos de I+D para Grupos de Investigación Emergentes", project reference GV/2012/020.

\section{REFERENCES}

[1] F. J. González Fernández, "Industrial Maintenance in Spain: how to optimize resources and reduce costs" (original: "El mantenimiento industrial en España: cómo optimizar recursos y ahorrar costes"). Sevilla, February 2012.

[2] J. Mubray, "Reliability-Centered Maintenance", $2^{\text {nd }}$ edition, Industrial Press Inc, 2001.

[3] W.T. Thomson, M. Fenger, "Current signature analysis to detect induction motor faults” IEEE Ind. Appl. Mag., pp. 26-34, Jul/Aug 2001. http://dx.doi.org/10.1109/2943.930988

[4] M. Fernández Cabanas, M. García Melero, G. Alonso Orcajo, J.M. Cano Rodríguez, J. Solares Sariego. Maintenance and diagnosis 


\section{SPECIAL FOCUS PAPER \\ ReCEnt EduCATIONAL EXPERIENCES In ELECTRIC MACHINE MAINTENANCE TEACHING}

techniques for rotating electric machinery. Marcombo-Boixareu Editores and ABB Service S.A, Barcelona, 1999.

[5] J. A. Antonino-Daviu, M. Riera-Guasp, J. R. Folch, and M. Pilar Molina Palomares, "Validation of a new method for the diagnosis of rotor bar failures via wavelet transform in industrial induction machines," IEEE Trans. Ind. Appl., vol. 42, pp. 990-996, 2006. http://dx.doi.org/10.1109/TIA.2006.876082

[6] M. Riera-Guasp, J. A. Antonino-Daviu, M. Pineda-Sanchez, R. Puche-Panadero, and J. Perez-Cruz, "A General Approach for the Transient Detection of Slip-Dependent Fault Components Based on the Discrete Wavelet Transform," IEEE Transactions Industrial Electronics, vol. 55, pp. 4167-4180, 2008. http://dx.doi.org/ 10.1109/TIE.2008.2004378

[7] J. Antonino-Daviu, J. Pons-Llinares, V. Climente-Alarcón, J. Roger-Folch, M. Riera-Guasp, "Educational laboratory test benches for induction motor fault diagnosis training", 6th IEEE International Conference on E-Learning in Industrial Electronics (ICELIE 2012), Montreal (CANADA), 25-28 October 2012

[8] J. Antonino-Daviu, M. Riera-Guasp, J. Pons-Llinares, J.Park, S.B. Lee, J. Yoo and C. Kral, "Detection of Broken Outer Cage Bars for Double Cage Induction Motors under the Startup Transient",
IEEE Transactions on Industry Applications, Vol. 48, No.5, Sept/Oct 2012, pp. 1539-1548. http://dx.doi.org/10.1109/ TIA.2012.2210173

[9] R. Balart, T. Boronat, L. Sánchez-Nácher, D. García-Sanoguera, O. Fenollar, "Use of new multimedia teaching platforms as support for teaching-learning in materials science", in proc. of the 5th International Technology, Education and Development Conference, Valencia, SPAIN, 7-9 March, 2011.

\section{AUTHORS}

J. Antonino-Daviu, J. Pons-Llinares, and V. Climente-Alarcón are with the Instituto de Ingeniería Energética, Universitat Politècnica de València, Camino de Vera s $\mathrm{n}$, 46022 Valencia, SPAIN (joanda@die.upv.es).

This article is an extended and modified version of a paper presented at the EDUCON2013 conference held at Technische Universität Berlin, Berlin, Germany from March 13-15, 2013. Received 08 May 2013. Published as resubmitted by the authors 21 May 2013. 